\title{
Spatiotemporal drought analysis in Bangladesh using the standardized precipitation index (SPI) and standardized precipitation evapotranspiration index (SPEI)
}

Mohammad Kamruzzaman ( $\sim$ milonbrri@gmail.com )

Bangladesh Rice Research Institute

Mansour Almazroui

King Abdulaziz University

\section{MA Salam}

Bangladesh Rice Research Institute

Anarul Haque Mondol

Monash University

Md. Mizanur Rahman

Bangladesh Rice Research Institute

Limon Deb

Bangladesh Rice Research Institute

Polash Kumar Kunda

Bangladesh Rice Research Institute

Md. Asad Uz zaman

Bangladesh Rice Research Institute

Abu Reza Md.Toufiqul Islam

Begum Rokeya University

\section{Research Article}

Keywords: Drought, Bangladesh, drought intensity, drought frequency

Posted Date: February 8th, 2022

DOI: https://doi.org/10.21203/rs.3.rs-1323693/v1

License: (c) (i) This work is licensed under a Creative Commons Attribution 4.0 International License. Read Full License 


\section{Abstract}

The lack of precipitation for an extended period is what meteorologists call a drought, and it results in low soil moisture and crop water stress. Drought has become one of the most important global challenges due to inadequate water supplies. Drought monitoring is frequently conducted using the SPI (standardized precipitation index) and the SPEI (standardized precipitation evapotranspiration index). The goal of this work is to use SPI and SPEI to investigate the differences in drought characteristics across different physiognomy types in Bangladesh and to highlight how drought characteristics change over time and spatial scales when considering different geomorphologies. This study used monthly precipitation and temperature data from 29 metrological stations for 39 years (1980-2018) for calculating SPI and SPEI values. To determine the significance of drought characteristic trends over different temporal and spatial scales, the modified Mann-Kendall trend test and multivariable linear regression (MLR) techniques were used. The results are as follows: (1) Overall, an increasing dry trend was found in Eastern hill regions, whereas decreasing trends were found rest of the regions in all time scale (range is from -0.008 year $^{-1}$ to -0.015 year $^{-1}$ for $3-$ month time scale). However, except for the one-month time scale, the statistically significant trend was identified mostly in the north-central and northeast regions, indicating that drought patterns migrate from the northwest to the center region. (2) Drought intensity increased gradually from the southern to the northern regions (1.26-1.56), and drought events occurred predominantly in the northwestern regions (27-30 times), indicating that drought meteorological hotspots were primarily concentrated in the Barind Tract and Tista River basin over time. (3) According to the MLR, longitude and maximum temperature can both influence precipitation. Findings can be used to improve drought evaluation, hazard management, and application policymaking in Bangladesh. This has implications for agricultural catastrophe prevention and mitigation.

\section{Introduction}

Drought is the most complicated of the recurrent extreme weather events since it is defined by a lack of rainfall over a considerable period of below-normal rainfall, and it can result in significant economic loss and human misery ${ }^{1}$. Drought has become more frequent and severe in many regions of the world, including Bangladesh, as a result of global warming and climate change (increasing temperatures and shifting rainfall patterns) ${ }^{2-4}$. The average global temperature is expected to rise by $0.20^{\circ} \mathrm{C}$ each decade for the rest of the $21 \mathrm{st}$ century at least, although the rate of growth will differ by area ${ }^{5}$. By the end of the twenty-first century, global temperatures are predicted to rise by 0.3 to $4.8^{0} \mathrm{C}^{6-8}$. According to some research, Bangladesh is warming faster than the rest of the world $7,9,10$, which is likely to lead to increased water demand and, as a result, a worsening of the country's drought.

Natural disasters are common in Bangladesh including floods, drought, cyclones, sea-level rise and salt intrusions. Currently, agriculture and water are two sectors that are seriously affected by the ongoing drought in the country. In the recent past, Bangladesh has been subjected to various degrees of drought, which have mostly damaged agricultural areas and resulted in enormous losses of food grains. Likewise, drought has an impact on the country's socio-economic environment and development efforts ${ }^{11}$. Bangladesh has had severe historical droughts in 1951, $1957,1961,1973,1975,1979,1981,1982,1984,1989$, and $1995^{11-13}$, with the 1995 drought resulting in a net loss of 377,000 tons of Aman rice ${ }^{14}$. According to Ahmed ${ }^{14}, 47 \%$ of the nation is at risk of drought, and $33 \%$ of the population lives in drought-prone regions. Drought reduced agricultural output by $25-30 \%$ in the northwestern region of Bangladesh in 2006, according to Habiba et. al.14. Despite the fact that drought planning and management in Bangladesh have received less attention than other hazards, drought is more devastating than floods and droughtrelated losses are larger than flood-related losses, according to research ${ }^{11,16,17}$. There has been a significant push to address drought management concerns, owing to the influence of climate change, the growing severity of drought 
occurrences, and human vulnerability. As a result, governments, scientists, and environmentalists are all working together to establish legislation that will help minimize the effects of drought.

To make matters worse, ecological over-exploitation of forest resources is causing soil erosion and harm to native plants, which in turn is causing the natural water cycle to become unbalanced. According to earlier studies, the main causes of drought are a lack of rainfall and an increase in temperature ${ }^{18}$. As a result, drought features at a specific location and time period may be assessed based on rainfall and temperature, and appropriate steps can be implemented to minimize drought frequency and intensity ${ }^{19}$.

The Drought Characteristic Index ( $\mathrm{DCl}$ ) is an indicator developed by the World Meteorological Organization (WMO) in 1992 and measures the cumulative effects and irregular water deficiencies of long-term drought conditions. It must be based on large-scale quantitative measurements over an extended time period and an accurate collection of historic records to be considered valid ${ }^{20}$.

The Palmer Drought Severity Index (PDSI) calculates the severity of any given drought by using climatologically appropriate precipitation as a proxy for water demand and assessing water loss based on definite precipitation discrepancies ${ }^{21}$. However, PDSI is spatially limited and hence cannot accurately explain large-scale drought changes $^{22}$. Thomas B. McKee et al. ${ }^{23}$ advocated that the PDSI be replaced by the standardized precipitation index (SPI), which has a wide range of applications in terms of time, space, and rainfall probability distribution. It can detect drought features across a large area at different scales. Precipitation, the SPI discovered, is the most critical factor in influencing the intensity and duration of droughts ${ }^{24}$. An extension of the Standardized Precipitation Index (SPI) is the Standardized Precipitation Evapotranspiration Index (SPEI). For the purpose of determining drought, the SPEI considers both precipitation and potential evapotranspiration (PET). Since the SPI does not take into account the impact of rising temperatures on water demand, the SPEI does. It is possible to compute the SPEI over time frames ranging from one to forty-eight months, just like the SPIClick or tap here to enter text. ${ }^{25}$. Drought-prone areas can benefit from the combined usage of SPEI and SPI, which are widely used in current research.

The pre- and post-monsoon seasons are the most common periods for the occurrence of drought in BangladeshClick or tap here to enter text. When monsoon rains begin later than expected, pre-drought conditions can linger throughout the monsoon season in extreme cases $^{26}$. The extent to which a place is vulnerable to drought varies. It is predicted that precipitation will continue to increase in the majority of Bangladesh's areas, although it is projected to decrease in the southwest, according to one study ${ }^{27}$. Drought features from the past can be used to make predictions about future droughts $^{28}$. As a result, it is critical to monitor the spatiotemporal characteristics of agricultural droughts in Bangladesh in order to anticipate adverse consequences and minimize potential losses and damages. Moreover, a drought monitoring and early warning system can help farmers and water managers plan for the most efficient use of water resources and maximize agricultural productivity.

Droughts occur as a result of climate change and a lack of soil moisture, resulting in reduced crop yields. One or more variables, such as large-scale downward air movement within the atmosphere or a deficiency of available moisture in the atmosphere, maybe directly responsible for a lack of rain. However, elements affecting Bangladesh's rainfall have not yet been identified. As a first for the country of Bangladesh, a multivariate regression model of precipitation ( $\mathrm{Y}$ ) was developed using data from this study, which included variables such as elevation, maximum and minimum temperatures, longitude and latitude. The conditional probability was also utilized to evaluate the sensitivity of drought indices to better depict dry/wet alternations in more complicated locations. 
Furthermore, the National Water Management Plan ${ }^{29-31}$ designated eight hydrological zones to plan the development of their water resources based on acceptable changes to their natural features. Southwest (SW), Northeast (NE), North Central (NC), Northwest (NW), South Central (SC), Southeast (SE), Eastern Hills (EH), and River and Estuary Region (RE) are the hydrological regions. Previously, no suitable activities in accordance with the Hydrological Region's drought risk management policy had been taken in Bangladesh.

This work has produced crucial information on changes in drought patterns, allowing researchers to learn more about anticipated future drought changes in Bangladesh. The article's primary research objectives include: (1) to compute the SPI and SPEI over a range of time scales using precipitation and evapotranspiration data; (2) Using the MannKendall test ( $\mathrm{M}-\mathrm{K}$ trend test), to evaluate the drought trend of diverse geographical characteristics; (3) to undertake a spatiotemporal analysis of Bangladesh's drought hotspots by measuring drought intensity, drought frequency, and the precipitation trend coefficient; (4) to examine the elements that contribute to changes in precipitation trends across diverse topography using the multivariable linear regression (MLR) approach. The findings may serve as a solid foundation for the government to expand the diversity of drought-prevention zones in the future when environmental preservation is a priority.

\section{Materials And Methods}

Study area. The study region includes all of Bangladesh and spans latitudes of $20^{\circ} 34^{\prime}$ to $26^{\circ} 38^{\prime} \mathrm{N}$ and longitudes of $88^{\circ} 01^{\prime}$ to $92^{\circ} 41^{\prime} \mathrm{E}$ in South Asia. On the west, north, and northeast, Bangladesh has borders with India; on the south, it shares a border with Myanmar. The Bay of Bengal, with its extensive coastline, marks the southern border (Figure 1). The highest point in the country's northern region is 105 meters above sea level, however, the rest of Bangladesh is no higher than 10 meters.

Bangladesh is one of the countries that are most at risk from the escalating effects of climate change on a global scale. It is frequently struck by natural calamities, including flooding, drought, tornadoes, and tidal bores ${ }^{32}$. Bangladesh has recently faced drought on a frequent and regular basis; on average, at least once every 2.5 years ${ }^{33}$. Between 2011 and 2015, the frequency of droughts in all categories increased dramatically ${ }^{1}$. Despite the fact that drought is widespread in Bangladesh, the northwest region is particularly prone to it because of the region's high degree of rainfall variation ${ }^{11}$. Additionally, this region is relatively arid and characterized by sandy soils, receiving significantly less rainfall than the national average ${ }^{12}$. The moisture retention capacity of sandy soils is lower than that of other soil types, while infiltration is higher ${ }^{15}$. In addition, drought in the region has been exacerbated by the construction of the Farakka barrage in the Ganges River's upper reaches.

Stations from the Bangladesh Meteorological Department (BMD) are now grouped into seven hydrological areas ${ }^{29}$ to study drought situations throughout the nation, as illustrated in Figure 1, taking into account geography and land usage as well as anomalies in rainfall. The seven hydrological regions are referred to as: (i) Southwest (SW, 3 stations), (ii) Northeast (NE, 2 stations), (iii) North Central (NC, 2 stations), (iv) Northwest (NW, 5 stations) (v) South Central (SC, 4 stations), (vi) Southeast (SE, 7 stations), and (vii) Eastern Hills (EH, 6 stations)

Observation Data. Because of the country's subtropical monsoon climate, temperatures, rainfall, and humidity all vary greatly from season to season throughout the year in Bangladesh. From March to May, there is a hot, humid summer; from June to September, there is a wet, warm, and rainy monsoon season; from October to November, there is autumn; and from December to February, there is a dry winter. In Bangladesh, three separate crop seasons exist pre-Kharif (March-June), Kharif (July-October), and Rabi (November-February). 
Bangladesh Meteorological Department (BMD) manages 35 meteorological stations throughout the country at the moment. Nonetheless, there are just 29 places with rainfall data going back more than 30 years. The 29 meteorological stations' monthly rainfall and temperature records from 1980 to 2018 were utilized to diagnose droughts in this study. Missing data is a key issue when using observational data. Averaged values from three surrounding sites were used to fill in the approximately $2 \%$ of data that was missing To obtain the spatial distribution of drought and pass the homogeneity test, we interpolated the data at a resolution of $1 \mathrm{~km}$ using inverse distance weighted (IDW) interpolation based on the placements of meteorological stations. Figure 1 depicts the research scope and the location of each site.

Between 1980 and 2018, there was a total of $2462.14 \mathrm{~mm}$ of rain recorded annually on the ground. Rainfall in Bangladesh peaks during the monsoon months (June to October) due to the weak humid depressions that are carried into Bangladesh by the moist monsoon winds ${ }^{9}$. One of the most notable aspects of Bangladesh's climate is the spatial and temporal unpredictability of the country's rainfall. Over the period 1980 to 2018, Bangladesh received rainfall ranging from approximately $1400 \mathrm{~mm}$ in the west to more than $4000 \mathrm{~mm}$ in the east. Meghalaya's elevation also contributes to the increased rainfall in the northeastern region.

Calculation of Standardized Precipitation Index (SPI). Drought conditions in the research area can be estimated using the Standardized Precipitation Index (SPI). SPI is an index that uses solely precipitation data. It is based on the chance of precipitation for a few consecutive months, and its major aim is to reflect the deficiency of precipitation across an area on several time scales relative to its climatology ${ }^{23}$. In spite of the fact that the SPI approach is not a drought forecasting tool, the SPI methodology has been used to identify dry or wet conditions and analyze their influence on water resources management. SPI can be calculated at several time intervals, including $1,3,6,12$, and 24 months ${ }^{34}$.

Unless researchers have a firm grasp on the required intervals, this strong feature of drought can generate an overwhelming amount of data ${ }^{35}$. The SPI is calculated mathematically using the cumulative likelihood of a certain rainfall event occurring at a given station. To begin, a two-parameter gamma density distribution function is used to fit the precipitation frequency of a meteorological station for each calendar month. The function of the gamma distribution is presented.

$f(x)=\frac{1}{\beta^{\alpha} \Gamma(\alpha)} x^{\alpha-1} e^{-x / \beta}$

Where, $\alpha$ and $\beta$ are the factors defining the shape and scale, respectively. Monthly precipitation is denoted by $\mathrm{X}$. The Thom method ${ }^{36}$ can be used to estimate the two parameters. Then, using the gamma cumulative distribution function, one may compute the cumulative probability $\mathrm{G}(\mathrm{x})$ at $\mathrm{x}$. Finally, the inverse of the cumulative standard normal distribution function is used to turn $\mathrm{G}(\mathrm{x})$ into the SPI value. Lue et al. ${ }^{37}$ introduced a thorough computation of SPI and drought categorization in their study.

Calculation of Standardized Precipitation Evapotranspiration Index (SPEI). As a result of global warming, surface evaporation changes have become more sensitive to droughts. The original SPI calculation algorithm is used to calculate the SPEI. The SPI is calculated using monthly precipitation data as the input. Monthly differences in precipitation and PET are used to calculate the SPEI. Using multiple time scales, the SPEI can be determined using this simple climatic water balance.

To determine the value of SPEI, the difference in the water balance is normalized as a log-logistic probability distribution. The probability density function can be expressed using the following equation: 


$$
f(x)=\frac{\beta}{\alpha}\left(\frac{x-\gamma}{\alpha}\right)\left[1+\left(\frac{x-\gamma}{\alpha}\right)\right]^{-2}
$$

Where the parameters scale, shape, and origin are denoted by $\alpha, \beta$, and $\gamma$, respectively. Thus, the probability distribution function can be described in terms of a probability density function.

$$
F(x)=\left[1+\left(\frac{\alpha}{x-\gamma}\right)^{\beta}\right]^{-1}
$$

3

Vicente-Serrano et al. ${ }^{34}$ defined the SPEl as follows:

$$
S P E I=W-\frac{C_{0}+C_{1} W+C_{2} W^{2}}{1+d_{1} W+d_{2} W^{2}+d_{3} W^{3}}
$$

4

When $P \leq 0.5, W=\sqrt{-2 \ln (P)}$ and when $\mathrm{P}>0.5, W=\sqrt{-2 \ln (1-P)}, \mathrm{C}_{0}=2.5155, \mathrm{C}_{1}=0.8028, \mathrm{C}_{2}=0.0203, \mathrm{~d}_{1}=1.4327$, $\mathrm{d}_{2}=0.1892, \mathrm{~d}_{3}=0.0013$.

Using the SPEI package for $\mathrm{R}^{38}$, the SPI and SPEI drought index were calculated for this article. It's a great research and practical tool for assessing drought conditions. SPI/SPEI values were used to classify the severity of the drought, as shown in Table 1. SPI/SPEI values with a reduction in rainfall are indicative of drought, while SPEI values with a rise in rainfall are indicative of wetter or more typical conditions.

Table 1

Classification of drought based on SPI/SPEI values

\begin{tabular}{|ll|}
\hline SPEI or SPI Values & Drought category \\
\hline 0.99 to -0.99 & Normal \\
-1.0 to -1.49 & Moderate drought \\
-1.5 to -1.99 & Severe drought \\
$\leq-2$ & Extreme drought \\
\hline
\end{tabular}

\section{Runs theory}

Drought characteristics include the duration of the drought, its severity, and its frequency. SPI/SPEI under normal conditions (SPI/SPEI $\geq-1$ ) is also calculated from the general technique when the absolute value of SPI/SPEI is calculated, which has a substantial impact on drought assessment. Thus, we employed Yevjevich's run theory ${ }^{39}$ to define the severity and frequency of droughts. The runs theory constructs a segment of the drought variable time series with all values less than or larger than the set threshold. This segment is referred to as a negative or positive run. The formula for calculating drought intensity is 


$$
S=\frac{\sum_{n=1}^{T}\left|S_{S P I / S P E I}-K\right|}{T}
$$

where drought intensity is denoted by $\mathrm{S}, S_{S P I / S P E I}$ denotes an SPI or SPEI value less than or equal to the drought threshold, $\mathrm{K}$ denotes drought threshold, which in this study is set to be less than or equal to -1 , indicating that the severity of the drought is greater than that of moderate drought, and $\mathrm{T}$ is the duration of the drought.

Drought frequency is a metric for determining how often a drought occurs in a certain area, and its formula is as follows:

$$
D F=\frac{n}{N} \times 100
$$

6

where $\mathrm{N}$ is the time period during which the site was detected, and $\mathrm{n}$ denotes the number of droughts that occurred at the site during that time period.

Conditional probability. The term "conditional probability" refers to the likelihood of occurrence of a particular event $A$ in the presence of another event B, i.e. Cp (A/B). However, Cp (SPI) in this study refers to the possibility of an of $\mathrm{SPEI}_{\text {drought }}$ occurring during an $\mathrm{SPI}_{\text {drought }}$ and vice versa for $\mathrm{Cp}(\mathrm{SPEI})$. The formula is as follows:

$C p(S P I)=\frac{T_{S P I / S P E I}}{T_{S P E I}}$ or $C p(S P E I)=\frac{T_{S P E I / S P I}}{T_{S P I}}(7)$

whereas $\mathrm{T}_{\mathrm{SPI}}$ and $\mathrm{T}_{\mathrm{SPEI}}$ reflect drought periods in a certain location over time depending on the SPI/SPEI value, $\mathrm{T}$ SPI/SPEI and $\mathrm{T}_{\text {SPEI/SPI }}$ indicate the times of droughts in an area based on the SPEI/SPI evaluation that drought has happened, while SPI/SPEI conducts a re-evaluation of the region's droughts.

Trend Test. The Modified Mann-Kendall test (MMK) was introduced by Hamed et al. ${ }^{40}$ to address the issue of serial correlation by the use of the variance correction approach. For computing, the MK test the modified variance (Var(S)) is applied ${ }^{41,42}$ and the subsequent Eqs. (8-11) are applied to compute the autocorrelation:

\begin{tabular}{|l|}
$\operatorname{Var}(\mathbf{S})=\operatorname{Var}(\mathbf{S}) \times\left(\frac{\mathrm{n}}{\overline{\mathbf{n}}}\right)$ \\
$\left(\begin{array}{l}\mathrm{n} \\
\overline{\mathrm{n}}\end{array}\right)=1+\left(\frac{2}{\mathrm{n}(\mathrm{n}-1)(\mathrm{n}-2)}\right) \times \sum_{\mathrm{k}=1}^{\mathrm{n}-1}(\mathrm{n}-\mathrm{k})(\mathrm{n}-\mathrm{k}-1)(\mathrm{n}-\mathrm{k}-2)^{\mathrm{r}} \cdot \mathrm{k}$ \\
$\mathrm{r}_{\mathrm{k}=}$ \\
$\frac{\left(\frac{1}{\mathrm{n}-\mathrm{k}}\right) \sum_{\mathrm{i}=1}^{\mathrm{n}-\mathrm{k}\left(\mathrm{x}_{\mathrm{i}}-\mathrm{x}\right)\left(\mathrm{x}_{\mathrm{i}+\mathrm{k}}-\mathrm{x}\right)}}{\left(\frac{1}{\mathrm{n}}\right) \sum_{\mathrm{i}=1}^{\mathrm{n}}\left(\mathrm{x}_{\mathrm{i}}-\mathrm{x}\right)^{2}}$
\end{tabular}

where $n^{*}$ and $r_{k}$ implies the modified coefficient of autocorrelated data and autocorrelation coefficient of k-th lag, respectively; $x$ denotes the mean of the time series. The significance of the trend at a $95 \%$ confidence interval of the $k$ th lag can be estimated by Eq. (12): 


$$
\left(\begin{array}{c}
-1-1.96 \sqrt{n=k-1} \\
\overline{n-k}
\end{array}\right) \leq r_{k}(95 \backslash \%) \leq\left(\begin{array}{c}
-1+1.96 \sqrt{n=k-1} \\
\overline{n-k}
\end{array}\right)
$$

The $95 \%$ confidence level is achieved if the $r_{k}$ satisfies the upper condition. Hence, the dependence of the data and influence of the autocorrelation between different time lags should be eliminated for estimating the trend.

In this study, we used the MMK test in place of the classical MK test because of its ability to eliminate the influence of autocorrelation on test significance. The traditional MK test does not consider autocorrelation, which is common in the hydro-climatological time series. The positive autocorrelation increases the likelihood of test significance and viceversa for negative autocorrelation ${ }^{40}$.

Sen's slope estimator. The nonparametric Sen's slope (SS) technique ${ }^{43}$ was employed in this study to estimate the rate of trend magnitude In time-series datasets, this method was used to determine the magnitude of a trend. In comparison to other methods, the impact of an outlier on-trend outcomes is negligible using this strategy ${ }^{44}$. The Sen's slope (SS) can be calculated by Eq. (13)

$$
\beta=\operatorname{Median}\left[\frac{x_{j}-x_{i}}{j-i}\right] \text { all } j>i
$$

13

Where $x_{j}$ denote the $j^{\text {th }}$ values and $x_{i}$ the $i^{\text {th }}$ values in observational data. A positive value of $\beta$ denotes an increase whereas a negative value indicates a decreasing rate of change.

Multivariable linear regression method. The method of multivariable linear regression (MLR) is used to construct a multiple regression model in which meteorological variables affect their geographical interpolation components. We use precipitation $(\mathrm{Y})$ as the dependent variable and altitude $(\mathrm{H})$, maximum temperature (Tmax), minimum temperature (Tmim), longitude (Lo), and latitude (La) as the independent variables. We assume that each independent variable has a linear effect on the dependent variable and that the mean value of precipitation changes evenly when one independent variable changes while the others remain constant. The present study built a multiple regression model of precipitation $(\mathrm{Y})$ for altitude $(\mathrm{H})$, maximum temperature (Tmax), minimum temperature (Tmin), longitude (Lo), and latitude (La), and estimated the residuals using the following expression:

$$
Y(H, T \max , \operatorname{Tmin}, L o, L a)=b 0+b 1 H+b 2 \operatorname{Tmax}+b 3 \operatorname{Tmin}+b 4 L o+b 5 L a+\epsilon
$$

\section{4}

where b1, b2, b3, b4, b5 are the unknown coefficients; b0 is a constant and $\otimes$ is the residual value 45

\section{Results}

Patterns of drought on a multi-scale. Monthly SPI and SPEI values were computed for 29 weather stations from 1980 to 2018 at five unique time scales (1, 3, 6, 12, and 24 months), as depicted in Fig. S1 (a-g). The SPI and SPEI values were then averaged across five timescales to define the drought conditions in Bangladesh. Wet/dry transitions are more obvious as the time scale shortens, while the sensitivity of SPI and SPEI measurements varies substantially. The 
$\mathrm{MM}-\mathrm{K}$ test reveals a downward trend in the SPEI value for Bangladesh's drought-prone NW area, whereas the SPI value shows an upward trend over several time scales (Table 2).

SPEI is more responsive to drought fluctuations than SPI since it incorporates evapotranspiration. The difference between SPI and SPEI was determined using conditional probability (Cp). 
Table 2

MK Trend test coefficient and significant coefficient (P) of SPI and SPEI on various time scales in different hydrologic regions of Bangladesh

\begin{tabular}{|c|c|c|c|c|c|c|c|c|}
\hline \multirow[t]{2}{*}{ Region } & \multicolumn{4}{|l|}{ SPEI } & \multicolumn{4}{|l|}{ SPI } \\
\hline & Scale & Trend $\left(y r^{-1}\right)$ & $Z$ value & P-value & Scale & Trend $\left(y r^{-1}\right)$ & Z -value & $P$ value \\
\hline & SPEI1 & -0.004 & -1.234 & 0.217 & SPI1 & 0.0031 & 0.7742 & 0.4388 \\
\hline & SPEI3 & 0.000 & 0.048 & 0.961 & SPI3 & 0.0067 & 1.2823 & 0.1997 \\
\hline \multirow[t]{6}{*}{$\mathrm{EH}$} & SPEI6 & 0.007 & 1.040 & 0.298 & SPI6 & 0.0144 & 1.8629 & 0.0625 \\
\hline & SPEI9 & 0.012 & 1.742 & 0.082 & SPI9 & 0.0230 & 2.5887 & 0.0096 \\
\hline & SPEI12 & 0.017 & 2.371 & 0.018 & SPI12 & 0.0259 & 3.1694 & 0.0015 \\
\hline & SPEI24 & 0.020 & 2.323 & 0.020 & SPI24 & 0.0298 & 3.2662 & 0.0011 \\
\hline & SPEI1 & -0.006 & -1.126 & 0.260 & SPI1 & -0.0100 & -2.2142 & 0.0268 \\
\hline & SPEI3 & -0.015 & -2.033 & 0.042 & SPI3 & -0.0183 & -2.3606 & 0.0182 \\
\hline \multirow[t]{6}{*}{ NC } & SPEI6 & -0.019 & -2.105 & 0.035 & SPI6 & -0.0200 & -2.2507 & 0.0244 \\
\hline & SPEI9 & -0.022 & -2.396 & 0.017 & SPI9 & -0.0215 & -2.3960 & 0.0166 \\
\hline & SPEI12 & -0.026 & -2.505 & 0.012 & SPI12 & -0.0257 & -2.6982 & 0.0070 \\
\hline & SPEI24 & -0.035 & -2.613 & 0.009 & SPI24 & -0.0358 & -2.8069 & 0.0050 \\
\hline & SPEI1 & -0.006 & -1.126 & 0.260 & SPI1 & -0.0100 & -2.2142 & 0.0268 \\
\hline & SPEI3 & -0.015 & -2.033 & 0.042 & SPI3 & -0.0183 & -2.3606 & 0.0182 \\
\hline \multirow[t]{6}{*}{ NE } & SPEI6 & -0.019 & -2.105 & 0.035 & SPI6 & -0.0200 & -2.2507 & 0.0244 \\
\hline & SPEI9 & -0.022 & -2.396 & 0.017 & SPI9 & -0.0215 & -2.3960 & 0.0166 \\
\hline & SPEI12 & -0.026 & -2.505 & 0.012 & SPI12 & -0.0257 & -2.6982 & 0.0070 \\
\hline & SPEI24 & -0.035 & -2.613 & 0.009 & SPI24 & -0.0358 & -2.8069 & 0.0050 \\
\hline & SPEI1 & -0.005 & -1.234 & 0.217 & SPI1 & -0.0020 & -0.5565 & 0.5779 \\
\hline & SPEI3 & -0.008 & -1.185 & 0.236 & SPI3 & 0.0000 & -0.0242 & 0.9807 \\
\hline \multirow[t]{6}{*}{ NW } & SPEI6 & -0.009 & -0.968 & 0.333 & SPI6 & 0.0028 & 0.4355 & 0.6632 \\
\hline & SPEI9 & -0.007 & -0.823 & 0.411 & SPI9 & 0.0090 & 1.1855 & 0.2358 \\
\hline & SPEI12 & -0.009 & -1.137 & 0.255 & SPI12 & 0.0097 & 1.1613 & 0.2455 \\
\hline & SPEI24 & -0.013 & -1.597 & 0.110 & SPI24 & 0.0052 & 0.8226 & 0.4107 \\
\hline & SPEI1 & -0.004 & -0.871 & 0.384 & SPI1 & -0.0043 & -0.8710 & 0.3838 \\
\hline & SPEI3 & -0.006 & -0.798 & 0.425 & SPI3 & -0.0046 & -0.7016 & 0.4829 \\
\hline \multirow[t]{2}{*}{ SC } & SPEI6 & -0.005 & -0.871 & 0.384 & SPI6 & -0.0039 & -0.5323 & 0.5945 \\
\hline & SPEI9 & -0.003 & -0.435 & 0.663 & SPI9 & -0.0001 & 0.0000 & 1.0000 \\
\hline
\end{tabular}




\begin{tabular}{|c|c|c|c|c|c|c|c|c|}
\hline \multirow[t]{2}{*}{ Region } & \multicolumn{4}{|l|}{ SPEI } & \multicolumn{4}{|l|}{ SPI } \\
\hline & Scale & Trend $\left(y r^{-1}\right)$ & $Z$ value & P-value & Scale & Trend $\left(y^{-1}\right)$ & Z -value & $P$ value \\
\hline & SPEI12 & -0.004 & -0.435 & 0.663 & SPI12 & -0.0016 & -0.1694 & 0.8655 \\
\hline & SPEI24 & -0.006 & -0.581 & 0.561 & SPI24 & -0.0012 & -0.1210 & 0.9037 \\
\hline & SPEI1 & -0.005 & -1.234 & 0.217 & SPI1 & -0.0020 & -0.5565 & 0.5779 \\
\hline & SPEI3 & -0.008 & -1.185 & 0.236 & SPI3 & 0.0000 & -0.0242 & 0.9807 \\
\hline \multirow[t]{6}{*}{ SE } & SPEI6 & -0.009 & -0.968 & 0.333 & SPI6 & 0.0028 & 0.4355 & 0.6632 \\
\hline & SPEI9 & -0.007 & -0.823 & 0.411 & SPI9 & 0.0090 & 1.1855 & 0.2358 \\
\hline & SPEI12 & -0.009 & -1.137 & 0.255 & SPI12 & 0.0097 & 1.1613 & 0.2455 \\
\hline & SPEI24 & -0.013 & -1.597 & 0.110 & SPI24 & 0.0052 & 0.8226 & 0.4107 \\
\hline & SPEI1 & -0.006 & -1.597 & 0.110 & SPI1 & -0.0050 & -1.1860 & 0.2356 \\
\hline & SPEI3 & -0.007 & -1.017 & 0.309 & SPI3 & -0.0060 & -1.2464 & 0.2126 \\
\hline \multirow[t]{4}{*}{ SW } & SPEI6 & -0.008 & -1.053 & 0.292 & SPI6 & -0.0057 & -0.7381 & 0.4605 \\
\hline & SPEI9 & -0.003 & -0.351 & 0.726 & SPI9 & 0.0031 & 0.2904 & 0.7715 \\
\hline & SPEI12 & 0.000 & -0.036 & 0.971 & SPI12 & 0.0062 & 0.5687 & 0.5696 \\
\hline & SPEI24 & -0.008 & -0.811 & 0.418 & SPI24 & 0.0000 & 0.0000 & 1.0000 \\
\hline
\end{tabular}

$N E=$ North East, NC=North Central, NW=North West, SC=South Central, SW=South West, SE=South East, and EH=Eastern Hill

Table 3 summarizes the $\mathrm{Cp}$ (SPI) and $\mathrm{Cp}$ (SPEI) values for various areas at multiple time scales. Cp (SPI) was 0.54,0.52,0.44 and Cp (SPEI) was 0.46, 0.48,0.56,0 in the southern coastal areas from 1980 to 2010 at 3- month time scale, and the difference in the results was not statistically significant $(P>0.05)$, indicating SPI and SPEI can be used together to validate drought conditions at a certain time in a certain area. In some areas and throughout particular time periods, however, SPI and SPEI exhibit vastly different characteristics of drought than one another $(P<0.05)$. For instance, from 1980 to 2018, Cp (SPI) dropped continually whereas Cp (SPEI) climbed consistently (Cp (SPI) was 0.56,0.21,0.43,0.14 and Cp (SPEI) was 0.44,0.79,0.57, 0.86 on a 1-month time scale from 1980 to 2018. Cp (SPEI) was greater than $\mathrm{Cp}(\mathrm{SPI})$ on the time scale over all regions. Dry/wet cycles in more complex regions are likely to be captured with greater accuracy by SPEI than by SPI, according to these findings. 
Table 3

The conditional probability of SPI and SPEI in different regions of Bangladesh throughout various time periods and time scales (Cp (SPI) and Cp (SPEI)). ('/' indicates that no drought exists, and hence the conditional probability cannot be calculated).

\begin{tabular}{|c|c|c|c|c|c|c|c|c|c|c|c|c|c|}
\hline \multirow[t]{2}{*}{ Region } & \multirow[t]{2}{*}{ Period } & \multicolumn{6}{|c|}{ Cp (SPI) } & \multicolumn{6}{|c|}{ Cp (SPEI) } \\
\hline & & 1 & 3 & 6 & 9 & 12 & 24 & 1 & 3 & 6 & 9 & 12 & 24 \\
\hline \multirow[t]{4}{*}{$\mathrm{EH}$} & $\begin{array}{l}1980- \\
1990\end{array}$ & 0.47 & 0.64 & 0.68 & 0.67 & 0.70 & 0.71 & 0.53 & 0.36 & 0.32 & 0.33 & 0.30 & 0.29 \\
\hline & $\begin{array}{l}1991- \\
2000\end{array}$ & 0.13 & 0.42 & 0.43 & 0.42 & 0.44 & 0.26 & 0.28 & 0.58 & 0.57 & 0.58 & 0.56 & 0.74 \\
\hline & $\begin{array}{l}2001- \\
2010\end{array}$ & 0.19 & 0.43 & 0.40 & 0.50 & 0.40 & 0.33 & 0.47 & 0.57 & 0.60 & 0.50 & 0.60 & 0.67 \\
\hline & $\begin{array}{l}2011- \\
2018\end{array}$ & 0.09 & 0.44 & 0.44 & 0.33 & 0.00 & 0.50 & 0.31 & 0.56 & 0.56 & 0.67 & 0.99 & 0.50 \\
\hline \multirow[t]{4}{*}{ NC } & $\begin{array}{l}1980- \\
1990\end{array}$ & 0.33 & 0.40 & 0.27 & 0.50 & 0.50 & I & 0.67 & 0.60 & 0.73 & 0.50 & 0.50 & / \\
\hline & $\begin{array}{l}1991- \\
2000\end{array}$ & 0.67 & 0.49 & 0.48 & 0.50 & 0.48 & 0.33 & 0.94 & 0.51 & 0.52 & 0.50 & 0.53 & 0.67 \\
\hline & $\begin{array}{l}2001- \\
2010\end{array}$ & 0.67 & 0.59 & 0.50 & 0.50 & 0.44 & 0.56 & 0.78 & 0.41 & 0.50 & 0.50 & 0.56 & 0.44 \\
\hline & $\begin{array}{l}2011- \\
2018\end{array}$ & 0.61 & 0.49 & 0.46 & 0.45 & 0.49 & 0.50 & 0.89 & 0.51 & 0.54 & 0.55 & 0.51 & 0.50 \\
\hline \multirow[t]{4}{*}{ NE } & $\begin{array}{l}1980- \\
1990\end{array}$ & 0.39 & 0.48 & 0.47 & 0.50 & 0.44 & 0.40 & 0.61 & 0.52 & 0.53 & 0.50 & 0.56 & 0.60 \\
\hline & $\begin{array}{l}1991- \\
2000\end{array}$ & 0.30 & 0.47 & 0.42 & 0.45 & 0.49 & 0.43 & 0.70 & 0.53 & 0.58 & 0.55 & 0.51 & 0.58 \\
\hline & $\begin{array}{l}2001- \\
2010\end{array}$ & 0.38 & 0.46 & 0.50 & 0.50 & 0.41 & 0.44 & 0.62 & 0.54 & 0.50 & 0.50 & 0.59 & 0.56 \\
\hline & $\begin{array}{l}2011- \\
2018\end{array}$ & 0.76 & 0.41 & 0.48 & 0.41 & 0.42 & 0.00 & 0.24 & 0.59 & 0.52 & 0.59 & 0.58 & 0.99 \\
\hline \multirow[t]{4}{*}{ NW } & $\begin{array}{l}1980- \\
1990\end{array}$ & 0.56 & 0.36 & 0.45 & 0.33 & 0.60 & I & 0.44 & 0.64 & 0.55 & 0.67 & 0.40 & I \\
\hline & $\begin{array}{l}1991- \\
2000\end{array}$ & 0.21 & 0.46 & 0.44 & 0.46 & 0.50 & 0.44 & 0.79 & 0.54 & 0.56 & 0.54 & 0.50 & 0.56 \\
\hline & $\begin{array}{l}2001- \\
2010\end{array}$ & 0.43 & 0.60 & 0.46 & 0.50 & 0.50 & 0.50 & 0.57 & 0.40 & 0.54 & 0.50 & 0.50 & 0.50 \\
\hline & $\begin{array}{l}2011- \\
2018\end{array}$ & 0.14 & 0.48 & 0.50 & 0.49 & 0.49 & 0.43 & 0.86 & 0.52 & 0.50 & 0.51 & 0.51 & 0.57 \\
\hline \multirow[t]{3}{*}{ SC } & $\begin{array}{l}1980- \\
1990\end{array}$ & 0.30 & 0.54 & 0.58 & 0.69 & 0.68 & 0.80 & 0.70 & 0.46 & 0.42 & 0.31 & 0.32 & 0.20 \\
\hline & $\begin{array}{l}1991- \\
2000\end{array}$ & 0.40 & 0.50 & 0.43 & 0.48 & 0.47 & I & 0.60 & 0.50 & 0.57 & 0.52 & 0.53 & I \\
\hline & $\begin{array}{l}2001- \\
2010\end{array}$ & 0.41 & 0.50 & 0.48 & 0.46 & 0.52 & 0.40 & 0.59 & 0.50 & 0.52 & 0.54 & 0.48 & 0.60 \\
\hline
\end{tabular}




\begin{tabular}{|c|c|c|c|c|c|c|c|c|c|c|c|c|c|}
\hline & $\begin{array}{l}2011- \\
2018\end{array}$ & 0.33 & 0.42 & 0.43 & 0.48 & 0.47 & 0.48 & 0.67 & 0.58 & 0.57 & 0.52 & 0.53 & 0.52 \\
\hline \multirow[t]{4}{*}{ SE } & $\begin{array}{l}1980- \\
1990\end{array}$ & 0.55 & 0.54 & 0.65 & 0.70 & 0.64 & 0.75 & 0.45 & 0.46 & 0.35 & 0.30 & 0.36 & 0.25 \\
\hline & $\begin{array}{l}1991- \\
2000\end{array}$ & 0.47 & 0.52 & 0.57 & 0.55 & 0.47 & 0.67 & 0.53 & 0.48 & 0.43 & 0.45 & 0.53 & 0.33 \\
\hline & $\begin{array}{l}2001- \\
2010\end{array}$ & 0.40 & 0.44 & 0.38 & 0.57 & 0.64 & 0.22 & 0.60 & 0.56 & 0.62 & 0.43 & 0.36 & 0.78 \\
\hline & $\begin{array}{l}2011- \\
2018\end{array}$ & 0.27 & 0.35 & 0.40 & 0.00 & 0.00 & I & 0.73 & 0.65 & 0.60 & 0.99 & 0.99 & 0.99 \\
\hline \multirow[t]{4}{*}{ SW } & $\begin{array}{l}1980- \\
1990\end{array}$ & 0.37 & 0.48 & 0.53 & 0.54 & 0.47 & 0.63 & 0.63 & 0.52 & 0.47 & 0.46 & 0.53 & 0.38 \\
\hline & $\begin{array}{l}1991- \\
2000\end{array}$ & 0.45 & 0.42 & 0.45 & 0.50 & 0.50 & 0.40 & 0.55 & 0.58 & 0.55 & 0.50 & 0.50 & 0.60 \\
\hline & $\begin{array}{l}2001- \\
2010\end{array}$ & 0.42 & 0.50 & 0.42 & 0.50 & 0.46 & 0.33 & 0.58 & 0.50 & 0.58 & 0.50 & 0.54 & 0.67 \\
\hline & $\begin{array}{l}2011- \\
2018\end{array}$ & 0.40 & 0.50 & 0.49 & 0.45 & 0.47 & 0.39 & 0.60 & 0.50 & 0.51 & 0.55 & 0.53 & 0.61 \\
\hline
\end{tabular}

$N E=$ North East, $N C=$ North Central, NW=North West, SC=South Central, SW=South West, SE=South East, and EH=Eastern Hill

To examine the overall trends in SPEl and SPI in Bangladesh, the non-parametric MM-K test was employed to investigate drought trends across many locations and time scales from 1980 to 2018. (Table 2). According to the trend statistics, drought conditions continued to deteriorate across the country from 1980 to 2018, except for the Eastern Hilly (EH) region. When SPI/SPEl was estimated with more lagged time scales, the SPEI downward trend was larger than that of SPI, and the drought trend was steadily growing.

On all time periods, the SPEl drought trend in the NC and NE regions was larger than that in the SW, SE, SC, and NW regions $\left(-0.015\right.$ year $^{-1}$ for 3-month in NC and NE, -0.006 year $^{-1}$ for 3-month in SC, -0.007 year $^{-1}$ for 3-month in SW, -0.008 year $^{-1}$ for 3-month in NW and SE), indicating that the degree of drought in central Bangladesh is growing and the drought trend is gradually changing from southwest to east.

Precipitation trend and factors affecting the precipitation over Bangladesh. To conduct a secondary analysis of the trend in Bangladesh's drought characteristics from 1980 to 2018, as seen in Fig. 2, we studied the meteorological changes at 29 stations in Bangladesh over four decades (1980-1989, 1990-1999, 2000-1910, and 2011-2018) using the nonparametric MMK test method considering precipitation data.

Between 1980 and1989s, $69 \%$ of stations demonstrated decreasing precipitation trends, although only $10 \%$ of the sites demonstrated significance $(P<0.05)$, with the magnitude of the trend ranging from -273.21 to $136.33 \mathrm{~mm}$ year $^{-1}$. Between 1990 and 1999, rainfall increased in the majority of the country (76\% of stations) except for seven stations, with the magnitude of the trend ranging from -10 to $144 \mathrm{~mm}_{\text {year }}{ }^{-1}$. However, the increasing/decreasing trends are all insignificant $(P>0.5)$. The negative trend was dominant in the north-eastern region of Bangladesh, while parts of the southwestern region has begun to exhibit negative tendencies. In contrast, decreasing rainfall trends were found in most of the country (76\% of stations) except for seven stations, during the years 2000-2009. The magnitude of the trend ranged from- 132 to $114 \mathrm{~mm}_{\text {year }}{ }^{-1}$. However, those trends are not significant $(P>0.5)$. Between 2010 and 
2010, the majority of sites in Bangladesh showed positive trends, while just $27.5 \%$ showed negative trends. The sites with the largest magnitude trends (166.27 mm year ${ }^{-1}$ ) from 1990 to 2018 were in eastern hilly regions.

Table 4

Regression equation relating geographical and climatic factors (elevation $(\mathrm{H})$, maximum temperature $(\mathrm{Tmax})$, minimum temperature (Tmin), longitude (Lo), and latitude (La)) to annual precipitation at meteorological stations across time. $\mathrm{P}(\mathrm{H}), \mathrm{P}(\mathrm{Tmax}), \mathrm{P}(\mathrm{Tmin}), \mathrm{P}(\mathrm{Lo})$, and $\mathrm{P}(\mathrm{La})$ represent the t-test result; a value less than 0.05 indicates that the variable is statistically significant.

\begin{tabular}{|c|c|c|c|c|c|c|c|}
\hline Period & Regression equation & $\mathrm{R}^{2}$ & $P(H)$ & $P\left(T_{\max }\right)$ & $P\left(T_{\min }\right)$ & $P\left(L_{0}\right)$ & $P\left(L_{a}\right)$ \\
\hline $\begin{array}{l}1981- \\
1990\end{array}$ & $\begin{array}{l}\mathrm{Y}=-7.37 \times \mathrm{H}-346.7 \times \mathrm{T}_{\max }+ \\
50.0 \times \mathrm{T}_{\min }+474.4 \times \mathrm{L}_{\mathrm{o}}+143.8 \times \mathrm{L}_{\mathrm{a}}-34240.4\end{array}$ & 0.49 & 0.02 & 0.00 & 0.49 & 0.00 & 0.03 \\
\hline $\begin{array}{l}1991- \\
2000\end{array}$ & $\begin{array}{l}\mathrm{Y}=2.37 \times \mathrm{H}-263.9 \times \mathrm{T}_{\max } \\
+165.5 \times \mathrm{T}_{\min }+421.6 \times \mathrm{L}_{\mathrm{o}}-45.9 \times \mathrm{L}_{\mathrm{a}}-30122.9\end{array}$ & 0.52 & 0.46 & 0.00 & 0.01 & 0.00 & 0.43 \\
\hline $\begin{array}{l}2001- \\
2010\end{array}$ & $\begin{array}{l}\mathrm{Y}=-1.80 \times \mathrm{H}- \\
381.4 \times \mathrm{T}_{\max }-73.1 \times \mathrm{T}_{\min }+384.2 \times \mathrm{L}_{\mathrm{o}}-188.5 \times \mathrm{L}_{\mathrm{a}} \\
-14616.2\end{array}$ & 0.49 & 0.57 & 0.00 & 0.31 & 0.00 & 0.00 \\
\hline $\begin{array}{l}2011- \\
2018\end{array}$ & $\begin{array}{l}\mathrm{Y}=-4.55 \times \mathrm{H}-288.3 \times \mathrm{T}_{\max } \\
+123.3 \times \mathrm{T}_{\min }+588.3 \times \mathrm{L}_{\mathrm{o}}-65.5 \times \mathrm{L}_{\mathrm{a}}-42926.6\end{array}$ & 0.59 & 0.23 & 0.00 & 0.09 & 0.00 & 0.30 \\
\hline
\end{tabular}

The multivariable linear regression (MLR) method was used to develop a multiple regression model of average annual precipitation over various time periods based on altitude $(\mathrm{H})$, maximum temperature (Tmax), minimum temperature (Tmin), longitude (Lo), and latitude (La), as well as to determine the model's significance coefficients (Table 4). The findings reveal that the annual precipitation average for each period is significantly affected by the maximum temperature and longitude. Precipitation, maximum temperature, and longitude all demonstrate negative trends significantly $(\mathrm{P}<0.05)$, indicating that precipitation declines with increasing longitude and maximum temperature.

Drought intensity. In terms of defining the temporal and spatial variability of drought, SPEI was more sensitive to drought assessment than SPI. According to Kamruzzaman et al. ${ }^{46}, 3$-month time scale is better able to detect drought events in Bangladesh than any other. Since SPEI was found to be a good indication of changes in drought, the run theory and 3-month SPEI were used to create a spatial distribution map for the inter-annual fluctuation of drought intensity (Fig. 3).

Drought areas with an intensity of more than 1.5 were primarily located in the northeast region and the southern coastal region of Bangladesh during the 1980s. However, in the 1990s, drought intensity values greater than 1.4 were found all over the country except for the coastal region and were dominant in the northwest region. In the 2000 s the drought intensity was found to be weaker than in other decades, with values less than 1.4 over most regions. However, from 2010 to 2018, the drought territory with an intensity of more than 1.4 changed from the southern coastal regions to the western part of the country.

Drought frequency. We used 3-month SPEI values from 29 meteorological stations in Bangladesh from 1980 to 2018 to identify drought meteorological hotspots based on drought frequency, calculating the frequency of moderate drought and above-normal drought at each station (Fig. 4). 
The findings indicate that from 1980 to 2018, the frequency of droughts exceeding moderate levels was between 3 and $4 \%$ at each of Bangladesh's 29 meteorological stations, implying that the majority of the country typically experiences a drought event every two years. Between 1980 and 1989, drought frequency was highest at Patuakhali and Khepupara stations, which were physically located in the southeast and south regions, respectively, with frequencies of 34 and 31 events, during the period. Between 1990 and 1999, the drought frequency reduced in the majority of Bangladesh; even in the southeast, a drought occurred just 6 times.

However, the drought frequency in Bangladesh dropped dramatically between 2000 to 2009. Droughts occurred primarily in the southeast and northeastern regions, particularly in locations such as Swandip, Feni, and Rangamati, where droughts happened 30, 28, and 27 times, respectively. Between 1990 and 2010, the eastern hilly region's drought frequency decreased to 13-19 times, except at Kutubdia, whereas drought frequency increased dramatically over the remaining regions. The greatest rise was observed in the northwest and southwest regions, where droughts occurred between 27 and 30 times.

\section{Discussion}

Our findings confirmed prior findings that the frequency of droughts has increased in the northwest and southwest areas of Bangladesh ${ }^{10,11,47-51}$. Three main factors, including erratic spatiotemporal rainfall behaviour, geographic position, and high temperature, can lead to a rise in the frequency of drought, all of which is supported by the existing literature ${ }^{42,52-54}$. Prodhan et al. ${ }^{52}$ used statistical tools to monitor drought status in Bangladesh and discovered that the drought trend in the northwest and southwest regions has gradually increased over the last decades, while the drought trend in the southeast and northeast regions has steadily decreased over the last decade. Climate change and warming is the leading cause for the diversification of drought phenomena ${ }^{10}$. Additionally, the country's monsoon rainfall pattern is influenced by an irregular atmospheric circulation pattern known as the Southern Oscillation (SO), which reflects a relationship with EL Nino, or the quasi-periodic warming of sea surface temperature (SST) ${ }^{42}$ in a phenomenon known collectively as El Nino-Southern Oscillation (ENSO). Low rainfall occurred during the years of moderate El Nino (2002-03 and 2009-10) and strong El Nino (2014-2016) ${ }^{55,56}$. The long-term dry phase increases as SST are closely associated with the rainfall pattern ${ }^{50,57}$. Bangladesh is also influenced by regional topography, with the Bay of Bengal in the south and the Mighty Himalayas in the north having a significant effect on rainfall and drought patterns in the country.

Our study found that the monthly maximum temperature is inversely correlated with longitude over a lengthy period of time. Simultaneously, Bangladesh's average temperature distribution is much longer than its latitude zonality. The monthly average temperature has been negatively correlated with altitude for many years, indicating that temperature, latitude, longitude, and altitude are the primary factors affecting drought and rainfall. Furthermore, the elements triggered by Bangladesh's internal geographic location and atmospheric circulation have an indirect relationship with irregular weather and climate occurrences. Rahman et al. ${ }^{58}$ discovered that active convective inputs in the Indian Ocean's subtropical zone can induce sinking airflow over the southwest continental region, limit precipitation, and cause temperature anomalies.

In Bangladesh, the uneven spatial distribution of rainfall is determined by atmospheric conditions and is impacted by longitude and geographic position ${ }^{59}$. The method of multivariable linear regression (MLR) was used to create a multiple regression model of mean annual precipitation on various timescales based on altitude $(\mathrm{H})$, maximum temperature (Tmax), minimum temperature (Tmin), longitude (Lo), and latitude (La), and to compute its significance coefficients (Table 4). The findings revealed that longitude and maximum temperature could notably affect the mean

Page $15 / 25$ 
annual rainfall in each timescale. Precipitation, maximum temperature, and longitude exhibited significant negative trends $(P<0.05)$, implying that higher longitude and temperature triggered less rainfall. This study highlights that the coefficient of influence of temperature and longitude on precipitation is lower than altitude. Thus, altitude is not a critical contributing factor for the spatial disparity of rainfall in the country; multiple geographic factors determine the rainfall. Based on the results of the regression analysis, annual precipitation drops by $1.80-7.37 \mathrm{~mm}$ for every $100 \mathrm{~m}$ of altitude rise, and yearly rainfall declines by $263.9-346.7 \mathrm{~mm}$ for each degree of temperature increase, while the factor with the highest impact is the change in longitude, under which the more northwest and western part of the country receives less annual precipitation.

According to the MMK test, we computed the trend variations of SPEI of various climatic zones on multiple periods and found that all climatic zones exhibited negative trends from 1980 to 2018, except for the eastern hill regions. The trend coefficient of northcentral and northeastern parts is also higher than that of the remaining area, indicating that the degree of drought in the northcentral and northeastern parts of the country has steadily intensified. The drought trend gradually shifted from the southwest to the east. In contrast, the precipitation trend showed positive trends transfer from the northwest to the east and converge in the southeastern region. Earlier drought studies on the western part of Bangladesh have revealed that most of the regional droughts have increased notably in intensity and duration, particularly in the northwest part of the country, while for the moderate drought category, the trend coefficient from west to east in the northeastern part is declining $11,47,49$. Thus, it is crucial to explore the distribution of drought characteristics in Bangladesh at the regional scale.

The pattern of drought frequency has undergone notable geographic position changes; the distribution of drought frequency is more in the northwest and southwest and less in the south and east. The primary cause is the low-lying floodplain in the northwest part. Less rainfall and higher maximum temperature lead to increased evaporation capacity, and the foothills of the mountains affect the highland thermodynamic vertical circulation process, with the development of an atmospheric circulation backdrop consisting of little rainfall and many drought events. Though the degree of drought in the country's central zone continues to rise, we observed that the northwest area is already a drought-prone zone on various time scales from 1980 to 2018. The drought hotspots are primarily in the northwest part, particularly in Barind Tract and Tista River basin. The reason for meteorological hotspots is that these regions are surrounded by the foothills of the Himalayan Mountain, making it hard for the southwest monsoon to release its moisture after the air in this region sinks, triggering this region to become a meteorological hotspot with recurrent drought events. This outcome is consistent with earlier works ${ }^{56,60,61}$. For example, Hossain et al. and Shahid et al. ${ }^{11,62}$ showed that the frequency and intensity of moderate drought events have increased in the northwest region. However,t Abedin et al., Abdullah and Islam et al. ${ }^{49,63,64}$ disagreed with the current finding. They found that moderate drought occurred more in southern and southwestern parts of the country compared to northwest parts. The distribution of drought characteristics over various periods suggests that a targeted drought control scheme, including strengthening the reservoir infrastructure facility regionally, developing rainwater harvesting tools, popularizing agricultural water-saving technology locality, and altering agricultural transplanting structure periodically, can be helpful for drought mitigation and adaption.

The findings of the SPEI outweighed the SPI over long periods, indicating that temperature was also a driving factor for drought occurrence as well as the mere absence of precipitation. This was true primarily for meteorological (3month) and agricultural droughts. Our results exhibited agreement with the previous studies of Homdee et al. and Fung et al. ${ }^{65,66}$. The main difference between SPI and SPEI is the extra meteorological factors applied to compute the SPEI indices, such as P and P-PET, respectively. SPI mainly considers climatic water supply parameters, while SPEI considers both climatic water demand and supply ${ }^{53,67}$. Cosistent conclusions were found with earlier cited works 
using the SPEI which underlined the importance of climatic water demand and supply in drought studies ${ }^{68-70}$. Although precipitation is a crucial driver of meteorological drought, the rising temperature can significantly influence meteorological drought severity ${ }^{34}$. Therefore, SPEI is a comparatively better indicator than SPI under climate change because it is susceptible to temperature variation.

Our research establishes a systematic framework for drought monitoring, evaluation, and risk management in Bangladesh, as well as providing guidance and potential for policy implementation. SPI and SPEI are both meteorological drought indicators that take into account a variety of factors such as precipitation, evaporation, and temperature, and have a wide range of applicability for determining regional drought status. Due to the many perspectives on and interests in drought monitoring from the weather, agricultural, and water conservancy sectors, SPI and SPEl are proving to be not entirely adequate for addressing the actual needs of the different stakeholders. in realtime drought monitoring. Thus, drought monitoring remains a long-term and critical task.

\section{Conclusions}

On multiple time and space scales, this study analyzed the meteorological and geographical drought characteristics in Bangladesh using SPEI, SPI, drought precipitation trend, drought intensity, and drought frequency. The following are the major conclusions:

(1) In specific places and time periods, there are considerable discrepancies in the drought characteristics between SPI and SPEl; Cp (SPI) decreases uninterruptedly while Cp (SPEI) rises continuously from 1980 to 2018. Moreover, Cp (SPEI) was larger than $\mathrm{Cp}$ (SPI) on all time scales, indicating that SPEI was more sensitive to drought assessment than SPI.

(2) On all time scales, the SPEI drought trend in the NC and NE regions was greater than that in the SW, SE, SC, and NW regions (- 0.015 year $^{-1}$ for 3-month in NC and NE, -0.006 year $^{-1}$ for 3-month in SC, -0.007 year ${ }^{-1}$ for 3-month in SW, -0.008 year $^{-1}$ for 3-month in NW and SE). This indicates that the central part of Bangladesh is becoming more drought-prone, and the drought trend is moving from the southwest to the east.

(3) The correlation coefficient between altitude and rainfall is lower than the correlation coefficient between maximum temperature and longitude, demonstrating that height is not the primary factor driving the regional unevenness of precipitation in Bangladesh (MLR). According to the correlations, differences in geographical location and maximum temperature are most likely to be the cause of erratic rainfall.

(4) We discovered that the intensity of drought in Bangladesh's eastern hilly region gradually decreased over time, while the intensity of drought in the southern region gradually increased to the northern (NW and SW) region (1.261.56), while drought events occurred primarily in the northwestern regions (27-30 times), indicating that drought meteorological hotspots were primarily concentrated in the Barind Tract and Tista River basin over time.

\section{Declarations}

\section{Acknowledgments}

The authors are grateful to the Bangladesh Meteorological Department (BMD) and Bangladesh Agricultural Research Council (BARC) for providing the rainfall and temperature data.

\section{Author contributions}

Page $17 / 25$ 
M.K designed the research, and wrote the manuscript; M.A.S., M.A., A.H.M., L.D., P.K.K. analyzed the data; M.M.R., M.A.Z, and A.R.M.T.I. helped in the preparation of the manuscript and subsequent revisions.

\section{Competing interests}

The authors declare no competing interests.

\section{Additional information}

Correspondence and requests for materials should be addressed to M.K.

\section{Data availability}

The datasets used and/or analysed during the current study available from the corresponding author on reasonable request.

\section{References}

1. Kamruzzaman, M., Hwang, S., Cho, J., Jang, M. W. \& Jeong, H. Evaluating the spatiotemporal characteristics of agricultural drought in bangladesh using effective drought index. Water (Switzerland) 11, (2019).

2. He, B. et al. Quantitative assessment and spatial characteristic analysis of agricultural drought risk in China. Natural Hazards 66, 155-166 (2013).

3. Kamruzzaman, M., Jang, M.-W. W., Cho, J. \& Hwang, S. Future changes in precipitation and drought characteristics over Bangladesh under CMIP5 climatological projections. Water (Switzerland) 11, (2019).

4. Almazroui, M., Saeed, S., Saeed, F., Islam, M. N. \& Ismail, M. Projections of Precipitation and Temperature over the South Asian Countries in CMIP6. Earth Systems and Environment (2020) doi:10.1007/s41748-020-00157-7.

5. IPCC. Technical summary of climate change 2007: the physical science basis. In: Solomon S et al (eds) Contribution of working group I to the fourth assessment report of the intergovernmental panel on climate change. (2007).

6. IPCC. IPCC (2014) Climate change 2014: IPCC fifth assessment synthesis report-summary for policymakers-an assessment of inter-governmental panel on climate change. (2014).

7. Ahmad, Q. K., Warrick, R. A., Ericksen, N. J., \& Mirza, M. Q. The implications of climate change for Bangladesh: a synthesis. In The Implications of Climate and Sea-Level Change for Bangladesh. Springer, Dordrecht. 1--34 (1996).

8. Owley, J. et al. Climate change challenges for land conservation: Rethinking conservation easements, strategies, and tools. Denver Law Review vol. 95 (2018).

9. Shahid, S. Recent trends in the climate of Bangladesh. Climate Research 42, (2010).

10. Rahman, M. R. \& Lateh, H. Climate change in Bangladesh: a spatio-temporal analysis and simulation of recent temperature and rainfall data using GIS and time series analysis model. Theoretical and Applied Climatology 128, (2017).

11. Shahid, S. \& Behrawan, H. Drought risk assessment in the western part of Bangladesh. Natural Hazards 46, (2008).

12. Paul, B. K. Coping mechanisms practised by drought victims (1994/5) in North Bengal, Bangladesh. Applied Geography 18, 355-373 (1998).

13. Banglapedia. National encyclopedia of Bangladesh. (2012). 
14. Ahmed, A. U. Bangladesh Climate Change Impacts and Vulnerability: A Synthesis. Change (2006).

15. Habiba, U., Shaw, R., \& Hassan, A. W. R. Drought risk and reduction approaches in Bangladesh. Springer, Tokyo. '131-164 (2013).

16. Alexander D. Changing perspectives on natural hazards in Bangladesh. Nat Hazards Obs 10, 1-2 (1995).

17. WBB. Water resource management in Bangladesh: steps towards a new national water plan, Report No. 17663BD. The World Bank Bangladesh, Dhaka. (1998).

18. Min, S.-K., Zhang, X., Zwiers, F. W. \& Hegerl, G. C. Human contribution to more-intense precipitation extremes. Nature 470, 378-381 (2011).

19. Wang, Q. et al. The alleviating trend of drought in the Huang-Huai-Hai Plain of China based on the daily SPEI. International Journal of Climatology 35, 3760-3769 (2015).

20. Mehr, A. D., Sorman, A. U., Kahya, E. \& Afshar, M. H. Climate change impacts on meteorological drought using SPI and SPEl: case study of Ankara, Turkey. Hydrological Sciences Journal 65, 254-268 (2020).

21. Jia, Y., Zhang, B. \& Ma, B. Daily SPEI Reveals Long-term Change in Drought Characteristics in Southwest China. Chinese Geographical Science 28, 680-693 (2018).

22. Maity, R., Suman, M. \& Verma, N. K. Drought prediction using a wavelet based approach to model the temporal consequences of different types of droughts. Journal of Hydrology 539, 417-428 (2016).

23. Thomas B. McKee, N. J. D. \& Kleist, J. THE RELATIONSHIP OF DROUGHT FREQUENCY AND DURATION TO TIME SCALES. in applied climatology (1993). doi:10.1002/jso.23002.

24. Ali, M., Deo, R. C., Maraseni, T., \& Downs, N. J. Improving SPI-derived drought forecasts incorporating synopticscale climate indices in multi-phase multivariate empirical mode decomposition model hybridized with simulated annealing and kernel ridge regression algorithms. Journal of Hydrology 576, 164-184. (2019).

25. Gao, X. et al. Temporal and spatial evolution of the standardized precipitation evapotranspiration index (SPEI) in the Loess Plateau under climate change from 2001 to 2050. The Science of the total environment 595, 191-200 (2017).

26. Banglapedia. National Encyclopaedia of Bangladesh; Asiatic Society of Bangladesh: Dhaka, Bangladesh, 2019. (2019).

27. Fahad, M. G. R. et al. Regional changes of precipitation and temperature over Bangladesh using bias-corrected multi-model ensemble projections considering high-emission pathways. International Journal of Climatology $\mathbf{3 8}$, (2018).

28. Gommes, R. \& F.Petrassi. Rainfall variability and drought in Sub-Saharan Africa. FOA Research, Extension and Training Division (1996).

29. WARPO. National water management plan. Volume 2: Main report. Water Resources Planning Organization Ministry of Water Resources. Dhaka, Bangladesh. (2001).

30. Mojid, M. A., Parvez, M. F., Mainuddin, M. \& Hodgson, G. Water Table Trend - A Sustainability Status of. Water 11, $1-15$ (2019).

31. Mahmud, K. \& Chen, C. J. Space- and time-varying associations between Bangladesh's seasonal rainfall and large-scale climate oscillations. Theoretical and Applied Climatology 145, 1347-1367 (2021).

32. Bangladesh Bureau of Statistics (BBS). Bangladesh Disaster-related Statistics 2015 Climate Change and Natural Disaster Perspectives; Ministry of Planning, Government of the People's Republic of Bangladesh: Dhaka, Bangladesh, 2015. (2015).

33. Mondol, M. A. H., Ara, I. \& Das, S. C. Meteorological Drought Index Mapping in Bangladesh Using Standardized Precipitation Index during 1981-2010. Advances in Meteorology 2017, (2017).

Page 19/25 
34. Vicente-Serrano, S. M., Beguería, S. \& López-Moreno, J. I. A multiscalar drought index sensitive to global warming: The standardized precipitation evapotranspiration index. Journal of Climate 23, (2010).

35. Karavitis, C. A., Alexandris, S., Tsesmelis, D. E. \& Athanasopoulos, G. Application of the Standardized Precipitation Index (SPI) in Greece. Water 3, 787-805 (2011).

36. H. C. S. Thom. A note on the Gamma distribution. Monthly weather review 86, 117-122 (1958).

37. Liu, B., Zhou, X., Li, W., Lu, C. \& Shu, L. Spatiotemporal characteristics of groundwater drought and its response to meteorological drought in jiangsu province, China. Water (Switzerland) 8, (2016).

38. Begueria, S. \& Vicente-Serrano, S. M. SPEl: Calculation of the Standardised Precipitation-Evapotranspiration Index. R package version 1.7. R-Package (2017).

39. Yevjevich, V. An Objective Approach to Definitions and Investigations to Continental Hydrologic Droughts. Colorado State University, Fort Collins, Colorado. (1967).

40. Hamed, K. H. \& Ramachandra Rao, A. A modified Mann-Kendall trend test for autocorrelated data. Journal of Hydrology 204, 182-196 (1998).

41. Jerin, J. N. et al. Spatiotemporal trends in reference evapotranspiration and its driving factors in Bangladesh. Theoretical and Applied Climatology 144, (2021).

42. Islam, H. M. T. et al. Spatiotemporal changes and modulations of extreme climatic indices in monsoondominated climate region linkage with large-scale atmospheric oscillation. Atmospheric Research 264, 105840 (2021).

43. Sen, P. K. Estimates of the Regression Coefficient Based on Kendall's Tau. Journal of the American Statistical Association 63, (1968).

44. Novotny, E. v. \& Stefan, H. G. Stream flow in Minnesota: Indicator of climate change. Journal of Hydrology $\mathbf{3 3 4}$ (2007).

45. Zhu, S. J., Sun, A. H., Zhang, Z. X. \& Wang, B. Multivariable linear regression equation for rice water requirement based on meteorological influence. Procedia Engineering 28, 516-521 (2012).

46. Kamruzzaman, M., Cho, J., Jang, M.-W. \& Hwang, S. Comparative Evaluation of Standardized Precipitation Index (SPI) and Effective Drought Index (EDI) for Meteorological Drought Detection over Bangladesh. Journal of The Korean Society of Agricultural Engineers 61, 145-159 (2019).

47. Alamgir, M., Shahid, S., Hazarika, MK, Nashrrullah, S., Harun, SB, and Shamsudin S. "'Analysis of meteorological drought pattern during different climatic and cropping seasons in Bangladesh,"'- 2015,"' J. Amer. Water Resour. Assoc. 51, 794-806 (2015).

48. Miah, M. G., Abdullah, H. M. \& Jeong, C. Exploring standardized precipitation evapotranspiration index for drought assessment in Bangladesh. Environmental monitoring and assessment 189, 547 (2017).

49. Islam, A. R. T., Shen, S., Hu, Z. \& Rahman, M. A. Drought Hazard Evaluation in Boro Paddy Cultivated Areas of Western Bangladesh at Current and Future Climate Change Conditions. Advances in Meteorology 2017, (2017).

50. Islam, A. R. Md. T. et al. Spatiotemporal distribution of drought and its possible associations with ENSO indices in Bangladesh. Arabian Journal of Geosciences 14, (2021).

51. Aziz, M. A. et al. Mapping of Agricultural Drought in Bangladesh using Geographic Information System (GIS). Earth Systems and Environment (2021) doi:10.1007/s41748-021-00231-8.

52. Prodhan, F. A., Zhang, J., Bai, Y., Sharma, T. P. P. \& Koju, U. A. Monitoring of Drought Condition and Risk in Bangladesh Combined Data From Satellite and Ground Meteorological Observations. IEEE Access 8, 9326493282 (2020). 
53. Uddin MJ, HuJ, Islam ARMT, Eibek KU, Z. A comprehensive statistical assessment ofdrought indices to monitor drought status in Bangladesh. Arab J Geosci (2020) doi:https://doi.org/10.1007/ s12517-020-05302-0.

54. Sarker, M. L. R. et al. An integrated method for identifying present status and risk of drought in Bangladesh. Remote Sensing 12, (2020).

55. Banu, S. et al. Impacts of El Niño Southern Oscillation and Indian Ocean Dipole on dengue incidence in Bangladesh. Scientific Reports 5, 1-9 (2015).

56. Ghose, B. et al. Rice yield responses in Bangladesh to large-scale atmospheric oscillation using multifactorial model. Theoretical and Applied Climatology 146, 29-44 (2021).

57. Chowdhury M.R and Ndiaye O. Climate change and variability impacts on the forests of Bangladesh-A diagnostic discussion based on CMIP5 GCMs and ENSO,". Int. J. Climatol. 37, 4768-4782 (2017).

58. Rahman, M. S. \& Islam, A. R. M. T. Are precipitation concentration and intensity changing in Bangladesh overtimes? Analysis of the possible causes of changes in precipitation systems. Science of the Total Environment 690, (2019).

59. Ahmed, M. K., Alam, M. S., Yousuf, A. H. M. \& Islam, M. M. A long-term trend in precipitation of different spatial regions of Bangladesh and its teleconnections with El Niño/Southern Oscillation and Indian Ocean Dipole. Theoretical and Applied Climatology 129, 473-486 (2017).

60. Zinat MRM, Salam R, Badhan MA, Islam, A. Appraising drought hazard during Boro rice growing period in western Bangladesh. International Journal of Biometeorology 64(10): 16, 1687-1697 (2020).

61. Ghose, B. et al. Rain-Fed Rice Yield Fluctuation to Climatic Anomalies in Bangladesh. International Journal of Plant Production 15, (2021).

62. Hossain, Md. N., Chowdhury, S. \& Paul, S. K. Farmer-level adaptation to climate change and agricultural drought: empirical evidences from the Barind region of Bangladesh. Natural Hazards 83, 1007-1026 (2016).

63. Abedin, M. A., Habiba, U., \& Shaw, R. Impacts of salinity, arsenic, and drought in southwestern Bangladesh. In R. Shaw, \& P. Tran (Eds.), Environment Disaster Linkages (pp. 165-193). (Community, Environment and Disaster Risk Management; Vol. 9). Environment Disaster Linkages 9, 165-193 (2012).

64. Abdullah S.M. Standardizedprecipitationevapotranspiration index (SPEI) based drought assessment in Bangladesh," in Proceedings of the 5th Proceedings of International Conference onEnvironmentalAspectsofBangladesh(ICEAB'14). in Standardizedprecipitationevapotranspiration index (SPEI) based drought assessment in Bangladesh, 40-44 (2014).

65. Homdee, T., Pongput, K. \& Kanae, S. A comparative performance analysis of three standardized climatic drought indices in the Chi River basin, Thailand. Agriculture and Natural Resources 50, 211-219 (2016).

66. Fung, K. F., Huang, Y. F. \& Koo, C. H. Assessing drought conditions through temporal pattern, spatial characteristic and operational accuracy indicated by SPI and SPEl: case analysis for Peninsular Malaysia. Natural Hazards vol. 103 (Springer Netherlands, 2020).

67. Yao, N., Li, Y., Lei, T. \& Peng, L. Drought evolution, severity and trends in mainland China over 1961-2013. The Science of the total environment 616-617, 73-89 (2018).

68. Ayantobo, O. O., Li, Y., Song, S. \& Yao, N. Spatial comparability of drought characteristics and related return periods in mainland China over 1961-2013. Journal of Hydrology 550, 549-567 (2017).

69. Jing-feng, H., Shu-chuan, T., Abou-Ismail, O. \& Ren-chao, W. Rice yield estimation using remote sensing and simulation model. Journal of Zhejiang University-SCIENCE A 2002 3:4 3, 461-466 (2002).

70. Li, X., Y. Li, A. Chen, M. Gao, I. J. Slette \& Piao, S. The impact of the 2009/2010 drought on vegetation growth and terrestrial carbon balance in Southwest China. Agricultural and Forest Meteorology 239-248,269-270 (2019)

Page $21 / 25$ 


\section{Figures}

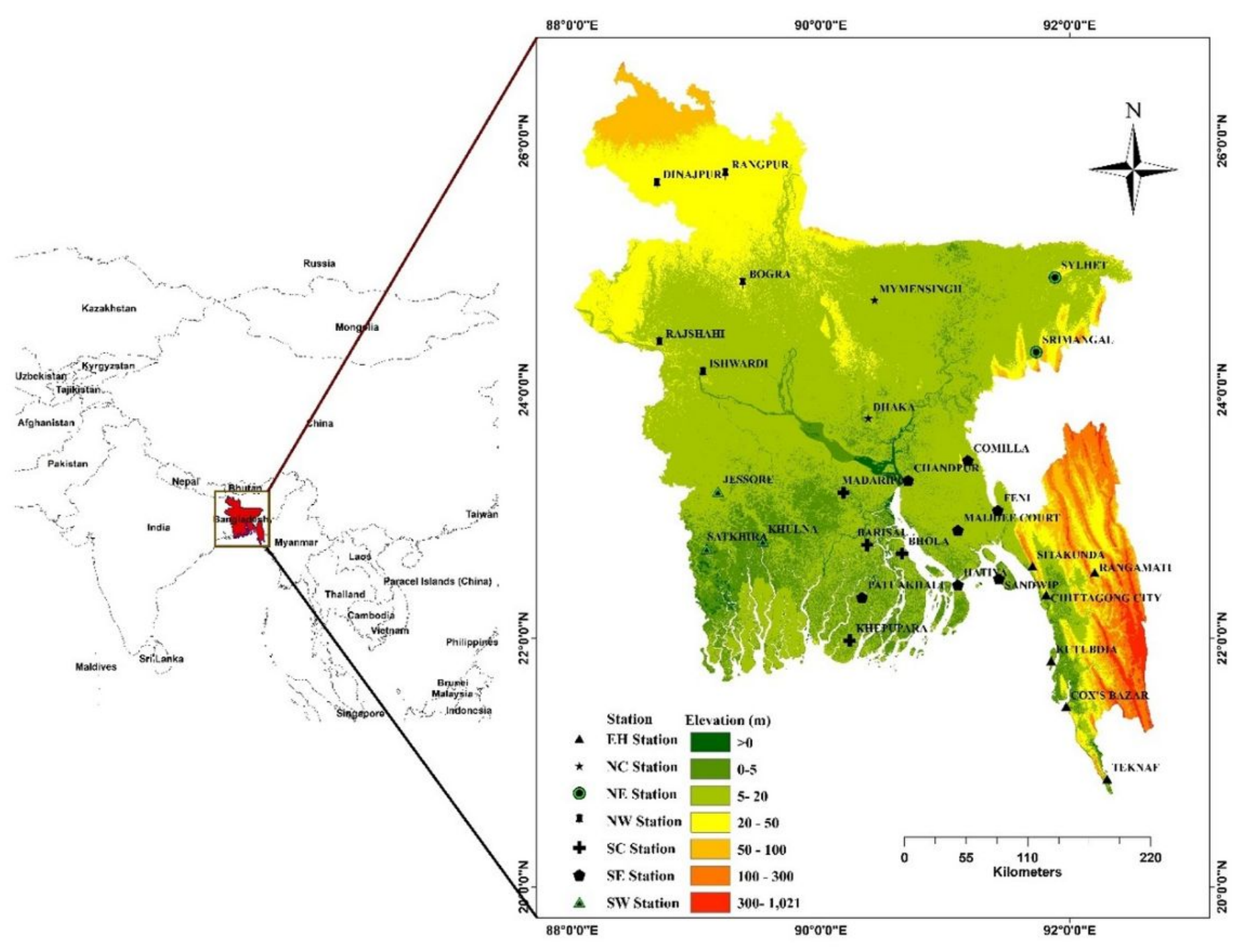

Figure 1

The hydrological regions of Bangladesh and the distribution of meteorological stations 

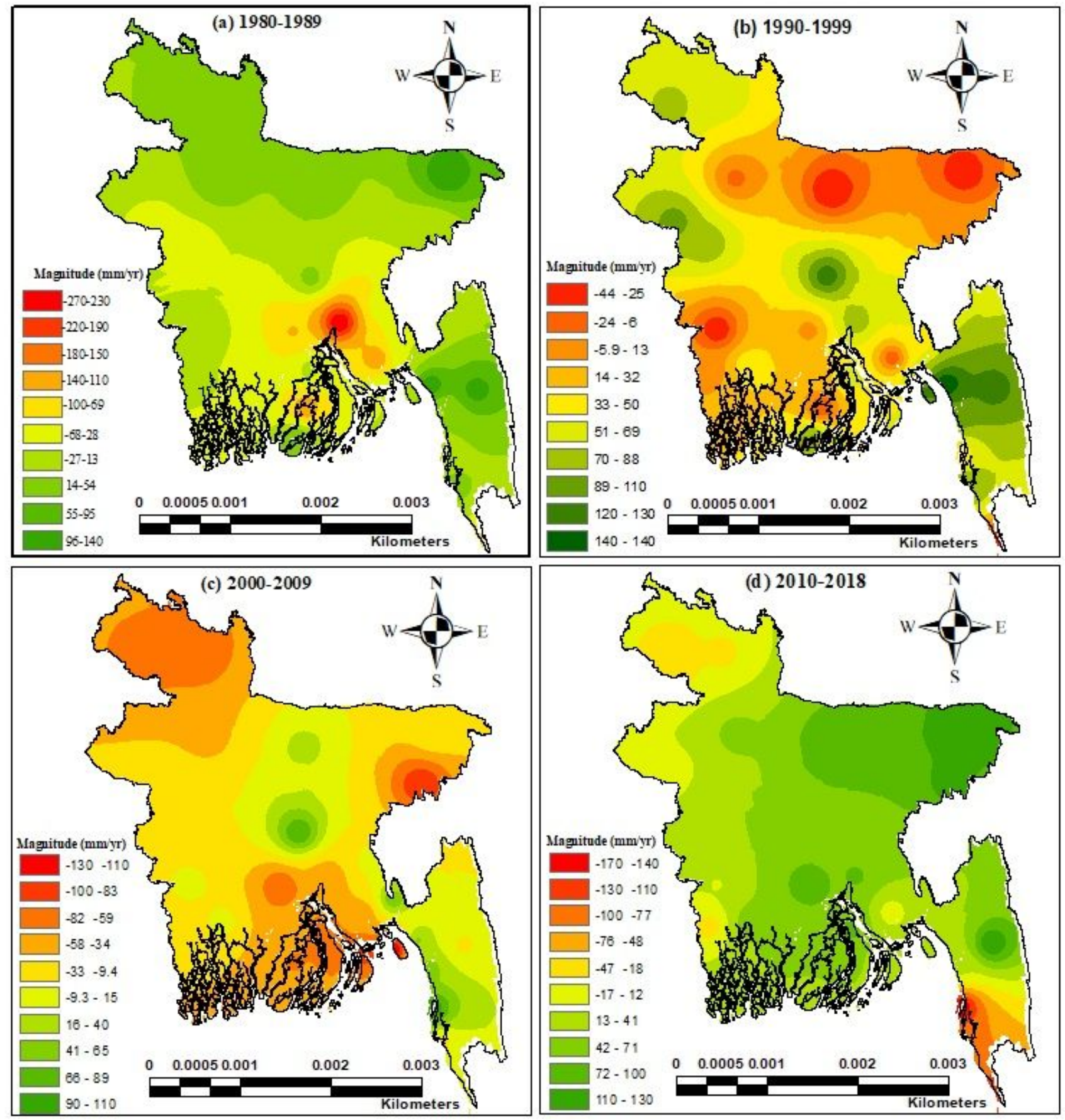

Figure 2

The MK Trend test coefficient for Bangladesh's precipitation throughout a range of time periods (1980-1989s, 19901999s, 2000-2009s, and 2010-2018s). 
(a) 1980-1989

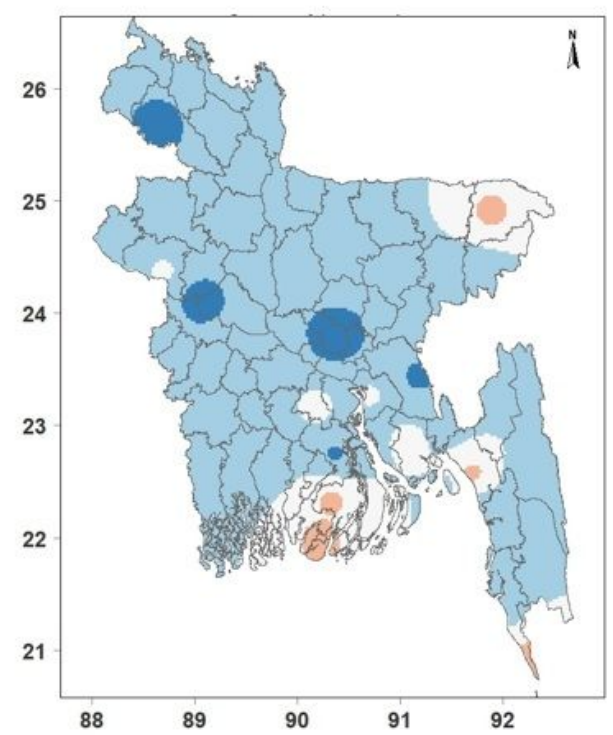

(d) $2010-2018$

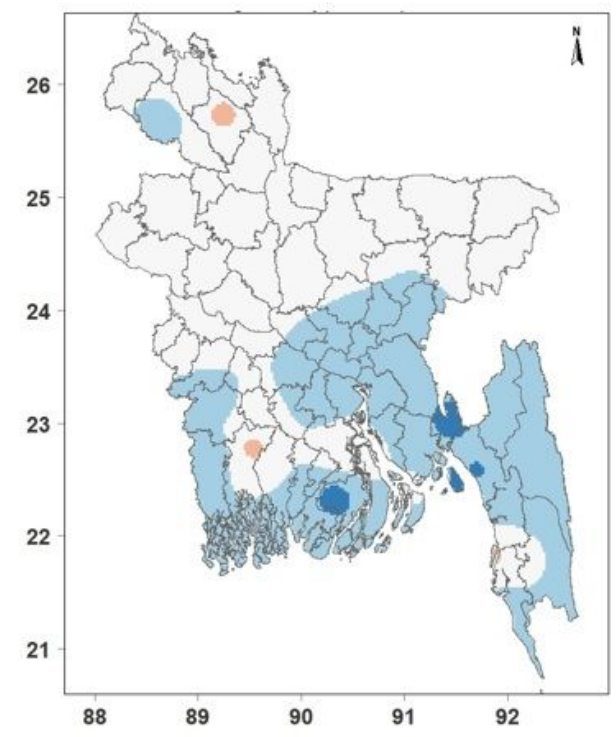

(b) 1990-1999

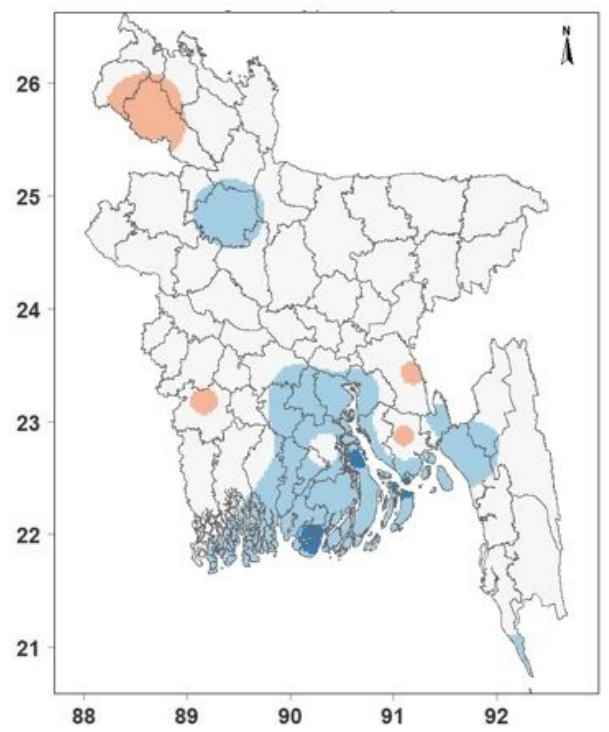

\section{Drought Intensity}

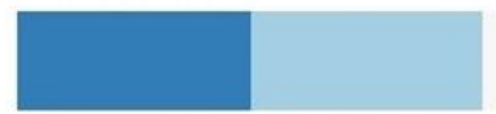

1.2 to 1.31 .3 to 1.41 .4 to 1.51 .5 to 1.61 .6 to 1.7

Figure 3

Based on 3-month SPEl, drought intensity during individual decades (1980-1989s, 1990-1999s, 2000-2009s, 20102018s) in Bangladesh 
(a) 1980-1989

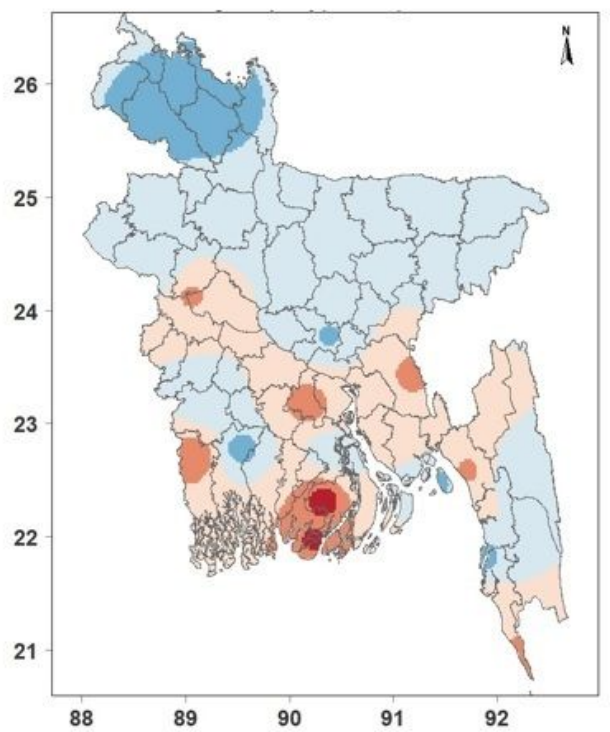

(d) 2010-2018

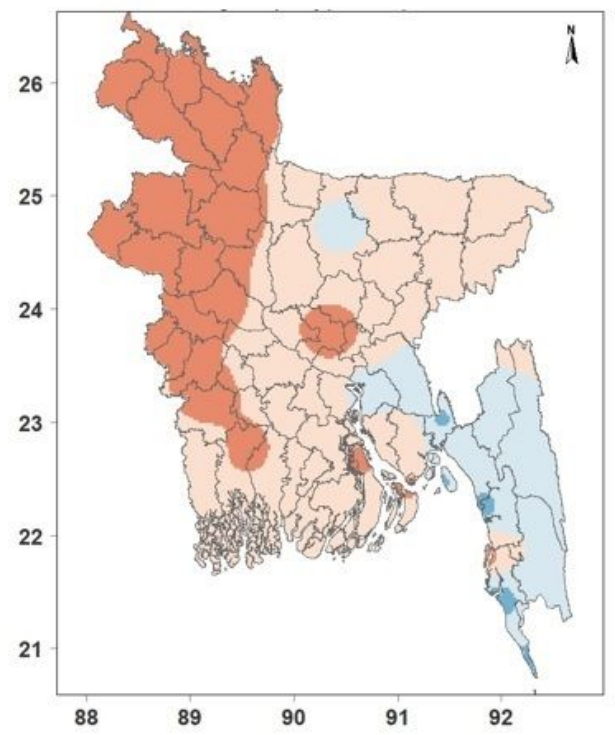

(b) 1990-1999
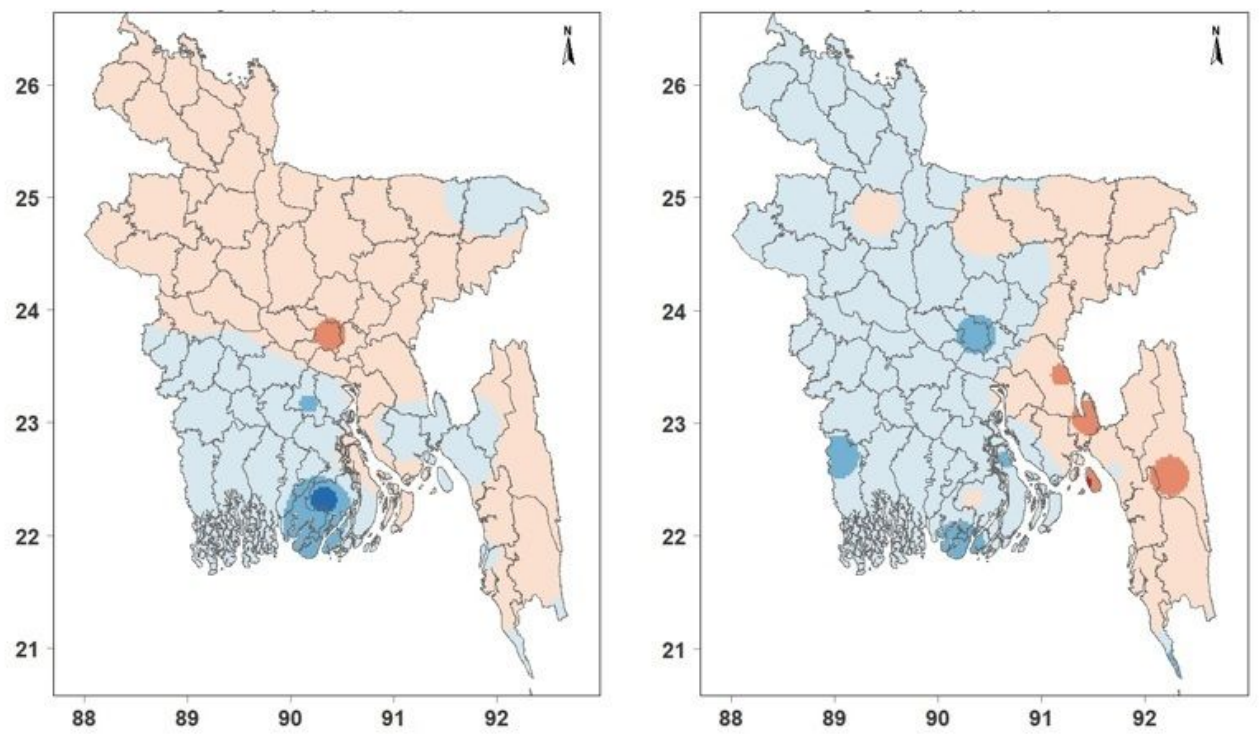

\section{Drought Frequency}

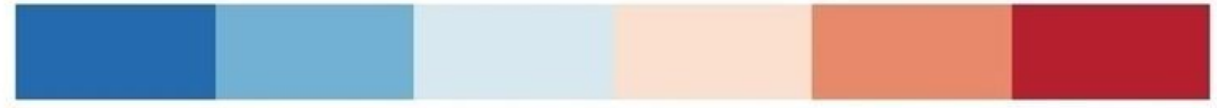

5 to 1010 to 1515 to 2020 to 2525 to 3030 to 35

Figure 4

Based on 3-month SPEI, drought frequency during individual decades (1980-1989s, 1990-1999s, 2000-2009s, 2010-2018s) in Bangladesh

\section{Supplementary Files}

This is a list of supplementary files associated with this preprint. Click to download.

- Suplimentaryinformation.docx 